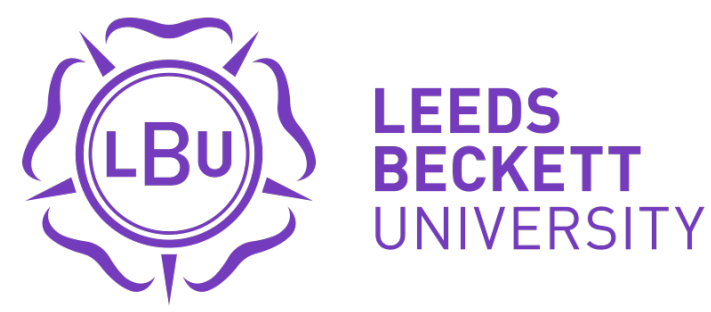

Citation:

Lofthouse, R and Whiteside, R and Rose, A (2021) Understanding coaching efficacy in education through activity systems: privileging the nuances of provision. International Journal of Mentoring and Coaching in Education. ISSN 2046-6854 DOI: https://doi.org/10.1108/IJMCE-02-2021-0036

Link to Leeds Beckett Repository record:

https://eprints.leedsbeckett.ac.uk/id/eprint/8028/

Document Version:

Article (Accepted Version)

Creative Commons: Attribution-Noncommercial 4.0

Citation: Lofthouse, R.M., Rose, A. and Whiteside, R. (2021), "Understanding coaching efficacy in education through activity systems: privileging the nuances of provision", International Journal of Mentoring and Coaching in Education, Vol. ahead-of-print No. ahead-of-print. https://doi.org/10.1108/IJMCE-02-2021-0036

The aim of the Leeds Beckett Repository is to provide open access to our research, as required by funder policies and permitted by publishers and copyright law.

The Leeds Beckett repository holds a wide range of publications, each of which has been checked for copyright and the relevant embargo period has been applied by the Research Services team.

We operate on a standard take-down policy. If you are the author or publisher of an output and you would like it removed from the repository, please contact us and we will investigate on a case-by-case basis.

Each thesis in the repository has been cleared where necessary by the author for third party copyright. If you would like a thesis to be removed from the repository or believe there is an issue with copyright, please contact us on openaccess@leedsbeckett.ac.uk and we will investigate on a case-by-case basis. 


\title{
Understanding coaching efficacy in education through activity systems: privileging the nuances of provision
}

\author{
Rachel Lofthouse, Ruth Whiteside, Anthea Rose \\ International Journal of Mentoring and Coaching in Education
}

\section{Purpose}

The research demonstrates the role of activity systems based in cultural historical activity theory as a means of analysing characteristics and efficacy of specific provisions of coaching in education.

\section{Design/methodology/approach}

Three examples of coaching in education were selected, involving 51 schools in England.

The three examples were reanalysed using activity systems. This drew on existing evaluation evidence gathered through interviews, questionnaires, focus groups and recordings of coaching.

\section{Findings}

In each example, the object of the coaching was to address a specific challenge to secure the desired quality of education. Using activity systems, it is possible to demonstrate that coaching has a range of functions (both intended and consequential). The individual examples illustrate the potential of coaching to support change in complex and diverse education settings.

\section{Research limitations}


The use of existing data from evaluations means that direct comparisons between examples are not made. While data was collected throughout the duration of each coaching programme, no follow-up data was available.

\section{Practical implications}

The analysis of the examples of coaching using activity systems provides evidence of the efficacy of specific coaching provision in achieving individually defined objectives related to sustaining and improving specific educational practices.

\section{Originality/value}

The research offers insights into how coaching in education might be better tuned to the specific needs of contexts and the challenges experienced by the individuals working in them. In addition, it demonstrates the value of activity systems as an analytical tool to make sense of coaching efficacy.

Key words: coaching, efficacy, activity systems 


\section{Introduction}

Coaching of teachers and leaders is becoming increasingly prevalent in education settings. In England, there has been a proliferation of freelance education coaching (Lofthouse, 2019) and professional training and literature in the field (e.g. Buck, 2020; Sherrington and Caviglioli, 2020; van Nieuwerburgh, 2017). Proponents of coaching in education draw on research evidence of its impact on improving student outcomes (Kraft et al., 2018), enhancing professional development opportunities (Cordingley et al., 2015; Knight, 2017; Lofthouse, 2019) and increasing teacher retention and wellbeing (Hollweck, 2017). However, a range of coaching types can share a common purpose, such as enhancing teachers' classroom practice, but apply different routines and practices. While coaching 'is recognized as a powerful vehicle for increasing performance, achieving results and optimizing personal effectiveness' (Bachkirova et al., 2014, p. 1), there is a need for new empirical research to develop greater clarity (Fletcher, 2012) and for more coaching practice to be anchored in research (Grant and O'Connor, 2019) in order to improve understanding and deployment of coaching in education.

This study contributes to the coaching in education evidence base through the analysis of three examples of coaching provision. The term provision is used throughout this study to refer to coaching which is developed and provided to a group of teachers or leaders and which adopts certain approaches and exists within a specific education context. The analytical lens adopted recognises each example of coaching as a unique activity system, with coaching as the 'collective endeavour' in specific education settings or 'systems' (Engeström, 1999). Each example of coaching provision was based in England and was undertaken between 2017 and 2019. In summary these are as follows:

Example 1: Headteacher coaching to improve the professional lives and capacities of headteachers 
Example 2: Teacher coaching for metacognitive pedagogies to improve pupils' attainment through changing teaching practices

Example 3: Teacher coaching for enhanced speech, language and communication practices to create successful and inclusive teaching and learning in multi-lingual settings

Activity systems are rooted in cultural historical activity theory (CHAT), which is attributed to the socio-cultural perspectives of Vygotsky $(1978,1986)$, subsequent work by Leont'ev (1981) and further developed by Engeström (1987, 1999, 2001, 2007). Analysis of the coaching examples using activity systems provides evidence of the efficacy of the specific coaching provision in achieving individually defined objectives related to sustaining and improving educational practices. In this study, activity systems are indicated as a pragmatic tool, allowing an 'iterative process of theorising and verification' (Briggs, 2007, p. 590). This study demonstrates the value of understanding the characteristics and impacts of distinct coaching provision to counter the over-generalisations of the role of coaching in education.

\section{Understanding Coaching Efficacy Using Activity Systems}

The three coaching examples in education in England included in this study conform to Kuusisaari's (2013) proposition that coaching can be described as enabling 'developing talk', through which peers working in coaching relationships aim to develop something new through 'collaborative considerations, constructions and solution findings' (p. 56). The examples are headteacher coaching (Example 1), teacher coaching for metacognitive pedagogies (Example 2) and teacher coaching for enhanced speech, language and communication practices (Example 3). As Bush et al. (2013) stated, 'People and organizations seek coaching because they want something to happen - and most of the time, that "something" is change' (p. 65). All forms of coaching in education, share the broad 
purpose to support the learning and/or wellbeing of educators and learners, with the

coachee's focus being their own and others' learning and development. Alongside this shared

purpose the three examples had unique characteristics and different objectives for change.

Explanatory information for each example is given in Table 1.

\begin{tabular}{|c|c|c|c|c|}
\hline $\begin{array}{l}\text { Coaching } \\
\text { case }\end{array}$ & $\begin{array}{c}\text { Example 1 } \\
\text { Headteacher coaching }\end{array}$ & $\begin{array}{c}\text { Example 2 } \\
\text { Teacher coaching for } \\
\text { metacognitive pedagogies } \\
\text { (maths focus) }\end{array}$ & $\begin{array}{c}\text { Example 3 } \\
\text { Teacher coaching for } \\
\text { enhanced speech, language } \\
\text { and communication } \\
\text { practices }\end{array}$ & $\begin{array}{c}\text { Elements of activity } \\
\text { system }\end{array}$ \\
\hline $\begin{array}{l}\text { Professional } \\
\text { context and } \\
\text { stated } \\
\text { coaching } \\
\text { objectives }\end{array}$ & $\begin{array}{l}\text { Primary, secondary and } \\
\text { special schools in England. } \\
\text { Recruitment and retention } \\
\text { of headteachers is a } \\
\text { growing problem. } \\
\text { Headteachers to experience } \\
\text { sustained wellbeing and } \\
\text { increased capacity in } \\
\text { leadership and } \\
\text { management. }\end{array}$ & $\begin{array}{l}\text { DfE Strategic School } \\
\text { Improvement Fund (SSIF) } \\
\text { project in } 10 \text { primary schools } \\
\text { in a Teaching School } \\
\text { Alliance (TSA) in rural } \\
\text { England, with } 50 \%-100 \% \\
\text { children from service } \\
\text { families. Lead teachers to } \\
\text { gain expertise for teaching } \\
\text { maths through metacognitive } \\
\text { pedagogies to raise pupil } \\
\text { attainment and to lead } \\
\text { development in school. }\end{array}$ & $\begin{array}{l}\text { Two federated inner-city } \\
\text { primary schools in England, } \\
\text { with }>90 \% \text { of children } \\
\text { speaking English as an } \\
\text { additional language (multiple } \\
\text { home languages). Teachers } \\
\text { and senior leaders to enhance } \\
\text { understanding of the speech } \\
\text { language and communication } \\
\text { needs (SLCN) of pupils and } \\
\text { develop adapted effective } \\
\text { pedagogies. }\end{array}$ & \multirow[t]{2}{*}{$\begin{array}{l}\text { The object of the } \\
\text { activity systems is to } \\
\text { address the identified } \\
\text { educational challenge } \\
\text { in each context } \\
\text { through supporting } \\
\text { the teachers and } \\
\text { headteachers whose } \\
\text { work is essential to } \\
\text { meet the goals. }\end{array}$} \\
\hline Coachees & $\begin{array}{l}\text { Thirty-nine headteachers } \\
\text { (both new and experienced } \\
\text { in role) who requested } \\
\text { coaching. }\end{array}$ & $\begin{array}{l}\text { Ten lead teachers (LTs), } \\
\text { with one LT per school } \\
\text { selected by senior leaders to } \\
\text { work with coaches and then } \\
\text { work with colleagues. }\end{array}$ & $\begin{array}{l}\text { All the teachers and senior } \\
\text { leaders in the two schools. }\end{array}$ & \\
\hline Coaches & $\begin{array}{l}\text { Ten professional coaches } \\
\text { working as associates for } \\
\text { the funded coaching } \\
\text { organisation. }\end{array}$ & $\begin{array}{l}\text { Three lead practitioners } \\
\text { (LPs) with the equivalent of } \\
\text { two full-time posts } \\
\text { appointed to facilitate the } \\
\text { SSIF project. }\end{array}$ & $\begin{array}{l}\text { Two experienced freelance } \\
\text { speech and language } \\
\text { therapists with background of } \\
\text { working in schools with } \\
\text { children and staff. }\end{array}$ & $\begin{array}{l}\text { The subject of the } \\
\text { activity systems is the } \\
\text { external coaches who } \\
\text { practice being } \\
\text { conscious of goals. }\end{array}$ \\
\hline $\begin{array}{l}\text { Outline of } \\
\text { coaching } \\
\text { approach }\end{array}$ & $\begin{array}{l}\text { Ontological coaching based } \\
\text { on common coaching } \\
\text { framework. Six two-hour } \\
\text { face-to-face coaching } \\
\text { sessions, with catch-up } \\
\text { phone calls. Headteacher } \\
\text { sets agenda. Coach helps } \\
\text { them to make meaning } \\
\text { through dialogue. } \\
\text { Headteachers meet at start } \\
\text { and end. Coaches engage in } \\
\text { group supervision. }\end{array}$ & $\begin{array}{l}\text { Specialised contextualised } \\
\text { coaching during scheduled } \\
\text { visits by lead practitioners to } \\
\text { lead teachers in their } \\
\text { schools, based on modelling } \\
\text { of teaching, joint planning, } \\
\text { co-teaching and debriefing. } \\
\text { Lead practitioners work } \\
\text { collaboratively. Lead } \\
\text { teachers form a network. }\end{array}$ & $\begin{array}{l}\text { Video-based coaching (using } \\
\text { selected video extracts of } \\
\text { teachers' own practice). } \\
\text { Cycle of three coaching } \\
\text { episodes per teacher with one } \\
\text { coach, using an appreciative } \\
\text { model to encourage curiosity } \\
\text { and shared sense making. } \\
\text { Coaching preceded by SLCN } \\
\text { training for teachers. }\end{array}$ & $\begin{array}{l}\text { The tools used are } \\
\text { suited to each } \\
\text { coaching approach } \\
\text { and context. } \\
\text { Mediating artefacts } \\
\text { include the coaching } \\
\text { rules (protocols) and } \\
\text { division of labour. All } \\
\text { participants exist } \\
\text { within and form } \\
\text { communities. }\end{array}$ \\
\hline $\begin{array}{l}\text { Schedule of } \\
\text { coaching and } \\
\text { funding }\end{array}$ & $\begin{array}{c}\text { Coaching funded by a } \\
\text { teacher union for } \\
\text { headteacher members. } \\
\text { Coaching Sept-July 2018- } \\
\text { 19, with two smaller } \\
\text { cohorts of headteachers } \\
\text { coached in preceding years. }\end{array}$ & $\begin{array}{l}\text { DfE funded Strategic School } \\
\text { Improvement paid salaries of } \\
\text { LPs (coaches) and release } \\
\text { time for teachers. Project ran } \\
\text { September } 2017 \text { to April } \\
2019 .\end{array}$ & $\begin{array}{l}\text { Speech and language } \\
\text { therapists (coaches) funded } \\
\text { through school continuing } \\
\text { professional development } \\
\text { (CPD) budget, during school } \\
\text { year 2017-18. Coaching } \\
\text { approach piloted in two } \\
\text { schools the previous year. }\end{array}$ & \\
\hline
\end{tabular}

Table 1. Explanatory information of the three examples of coaching 
In all three examples, the coaching provision involved a sequence of one-to-one conversations between coaches and coachees with continuity of the partnership assured. The coaching was complemented by professional participation of the coachees in cohorts, although the nature and extent of this varied across the examples. The coaching provision was typified by one-to-one conversations which drew on the coach's skills of 'questioning, active listening, and appropriate challenge in a supportive and encouraging climate' (van Nieuwerburgh, 2012, p. 17); however, the individual characteristics of each example demonstrate that coaching cannot be assumed to be a monolithic approach (Grant, 2013). The coaches fulfilled one, or more, of the coaches' roles defined by Killion (2009): being specialists in curriculum or instruction (teaching and learning), facilitating learning for adults in the school, and being catalysts for change. The coaches were not direct colleagues or line managers of the teachers or school leaders whom they were coaching. The coaching was contracted through agreements and commitments made by coaches and coachees (Lee, 2013), and these agreements also involved the school leadership team and/or funder of the coaching work. The three examples could be considered coaching in the workplace, which Grant (2013) defined as formal coaching provided under contract with professional external coaches, rather than workplace coaching conducted through coaching conversations with employees provided by supervisors or colleagues with some coaching training.

Coaching is designed to create opportunities for the coachee to move through a selfregulatory cycle influenced by their individual goal setting. This means that judging the personal impact of coaching implies acknowledging that its value must be felt by the coachee (Grant, 2013). However, for education professionals, it is necessary to reconcile the coachee's personal development with the impact of their work as an educator, and therefore judging the wider efficacy of coaching needs to reflect this relationship. Therefore, to judge the impact and efficacy of the three coaching examples, it was appropriate to take Biesta's 
(2020) questions and to ask 'effective for what?' and 'effective for whom?' These questions imply efficacy of coaching being judged both on the level of the coachee's personal and professional changes and on their impact on colleagues, students and communities whom they work with and for.

Activity systems, which are based in CHAT (Engeström, 1987, 1999, 2001, 2007), can be used to understand the dynamics influencing practices in educational settings. Such activity systems are exemplified through the following exemplary vignette, which is representative of practices shared informally by teachers and school leaders related to coaching for staff wellbeing.

Staff wellbeing is the object of the coaching activity system and is driven by members of the school leadership team who are the subjects. The object gives purpose to the work of the wider school staff, and the nature of the object is both tangible (e.g. staff absence rates, wellbeing survey results) and intangible, including how staff experience the school culture and the maintenance or alteration of existing power relations. A wellbeing plan acts as a tool, influencing the ways that colleagues across the school prioritise actions, and several staff are trained and deployed as wellbeing coaches. Additional tools such as mindfulness sessions are utilised. These mobilise and corral resources and time, are dependent on agreed rules exercised within the professional community and consequently create a division of labour. The rules, community and division of labour are mediating artefacts (Engeström, 1987) in the activity system, and the dynamics between them will determine the resulting outcomes of the object.

Inevitably, multiple activity systems co-exist in schools, and people are engaged in more than one activity at a time. Even working towards success under a quality assurance or inspection framework is likely to create multiple activity systems, which are each framed by 
shared motivations (e.g. to improve staff and student mental health and wellbeing and to increase examination results). This becomes even more complex when the same subject has contrasting motivations for their actions. Despite this, activity systems can be used by researchers, practitioners and policy makers to disentangle and understand the complexities and tensions of professional development practices situated in education settings dominated by standards discourses. Wilson (2014) illustrated this in her examination of teacher education through CHAT, which used a number of studies to highlight that activity systems are not static and that school-based mentoring (for example) may be in tension. This can mean that a mentor may be influenced by an activity system which prioritises pupil progress in their role as class teacher rather than privileging their role as mentor for the professional development of their student teacher.

In earlier research, one of the co-authors used activity systems to review evidence for the efficacy of peer coaching of teachers by teachers in English secondary schools (Lofthouse and Leat., 2013). While that research demonstrated the perceived value of coaching held by the coaching participants, it also revealed that the dominant culture of performativity (Ball, 2003) was so strong that coaching often faced resistance from other colleagues. The resulting dissonance experienced by coaching participants created contradictions within the dominant activity system, but the powerful performative culture was too strong to allow such contradictions to result in new objects either for school learning or professional development (Lofthouse and Leat, 2013). This was particularly evident when coaching was co-opted for, or clashed with, managerial cultures which demanded accountability and surveillance. In England, the effects of performativity remain pervasive. It even impacts teachers of non-core subjects, as illustrated by Thorpe and Kinsella (2020) in their comparative study in England and New Zealand of arts teachers' autonomy and perspective of whom they are accountable to. 
This new study returns to activity systems as the analytical lens to understand coaching but does so with more precision to understand the dynamic elements and efficacy of each of the coaching examples individually. In this analysis, coaching is the activity, that is, the collective endeavour made up of specific and localised social practice undertaken in the present and related to the past (historical) context. Figure 1 is a broad representation of a coaching activity system which uses the authors' current definition of coaching in education:

Coaching in education is an interpersonal and sustained dialogue-based practice. The coach works with a coachee to facilitate self-reflection and effective decision-making and action in the context of their own personal and professional challenges. 
The coach deploys TOOLS such as language (e.g. coaching questions) frameworks or models (e.g.

GROWTH coaching) and resources (e.e.

materials \& training) to support progress towards the object.

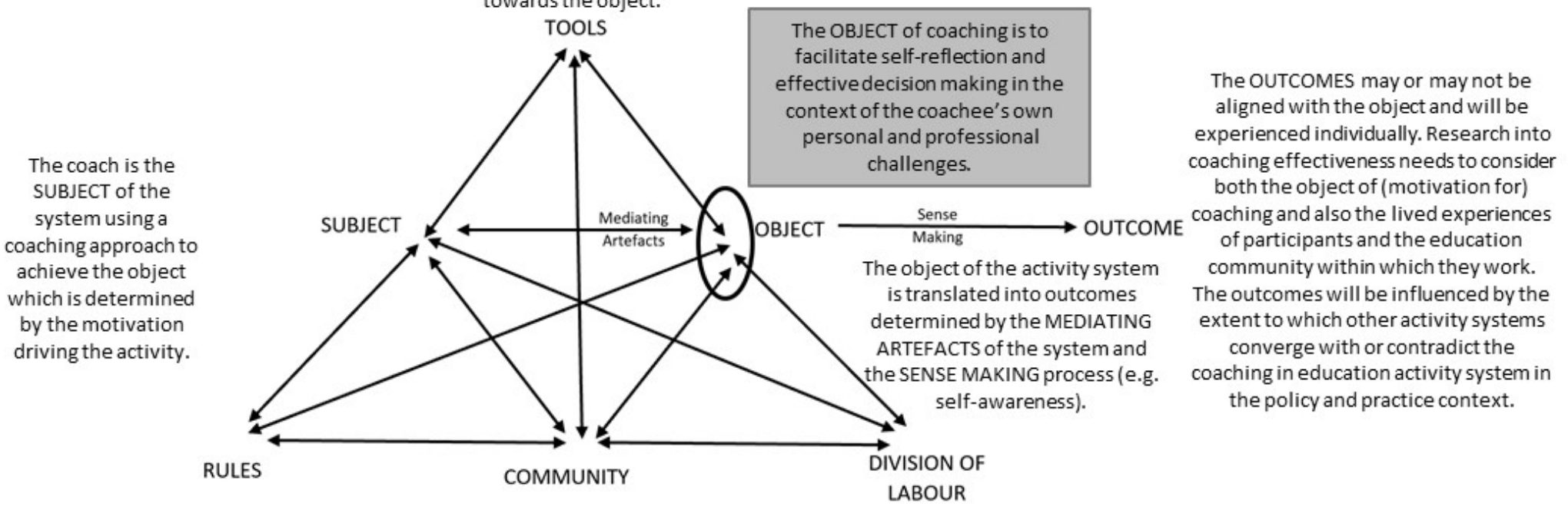

The RULES, COMMUNITY and DIVISION OF LABOUR are MEDIATING ARTEFACTS which influence the coachee's progress towards, and experience of achieving (or not), the object. They include the nature of coaching (a managed 1-1 conversation), the 'contracting' which frames the coaching, the relationship between coach and coachee and the communities that exist or are formed (e.g. cohorts of coachees, wider colleagues), and the ways that roles are adopting (e.g. respective contributions to coaching dialogue, the responsibilities assumed, power held or trust created).

Figure 1. Coaching in education as an activity system; coaching is an inter-personal and sustained dialogue-based practice. 


\section{Method}

The core research question of this study was 'How can activity systems be used as an analytical tool to understand the functions and efficacy of coaching provision in education?'

Each example of coaching used in this study has been the subject of prior evaluative, mixed-methods qualitative research undertaken by one or more of the co-authors (summarised below). The examples were selected for reconsideration though the lens of activity systems because the details of them were well known to the authors and data already existed. As they were all also situated in England and occurred in a three-year period, they were also subject to similar policy-level influences. Like much coaching effectiveness research, the original data from the three examples in this new analysis had a descriptive and qualitative nature and was largely based on self-reporting (Grant, 2013). The purpose of the original research was largely evaluative, asking the core questions of how effective each coaching provision was. Each example was researched independently, and thus, the methods adopted were attuned to research questions specific to each example as explained below.

The evaluation of Example 1, headteacher coaching, was funded by the National Education Union (who commissioned the coaching) and followed a cohort of 39 headteachers and their coaches through their participation in coaching during the school year 2018-19. The headteachers led primary and secondary schools, a secondary Pupil Referral Unit, a sixth form college and an independent special school. Some of the headteachers were new in post; others were more experienced, with some having been a headteacher in more than one setting. Online questionnaires completed by headteachers in Terms 2 and 3 of the school year were complemented by semi-structured telephone interviews of headteachers and coaches at two points in the year and headteacher focus groups following the completion of the coaching. The sample sizes were as follows: 31 (of the 39) headteachers completed at least one questionnaire, nine were interviewed and 13 headteachers attended one of two focus 
groups. In addition, six of the 10 coaches were interviewed who between them had coached 24 of the 39 headteachers. The design of the focus group discussions allowed participants to reflect on the extent to which their own and the coaches' expectations of the coaching outcomes had been achieved (Lofthouse and Whiteside, 2020).

The evaluation of Example 2, teacher coaching for metacognitive pedagogies (Lofthouse and Rose, 2019) was a condition made by the Department for Education who funded the Strategic School Improvement Fund (SSIF) project that the coaching was fundamental to. The SSIF project was facilitated by a Teaching School Alliance (TSA) as part of their remit 'as a critical vehicle for delivering both an uplift in the quality of teaching and a school improvement system led by schools for schools' (Gu et al., 2015, p. 15). A theory of change methodology (Laing and Todd, 2015) was used which 'articulates explicitly how a project or initiative is intended to achieve outcomes through actions, while taking into account its context' (p. 3). A theory of change diagram was constructed for each of the 10 schools. Each theory of change diagram was based on interviews with the three lead practitioners (LPs) employed for the SSIF project once they had established an initial working knowledge of the schools they were attached to. These were the schools that the LPs went on to work in as coaches, predominantly coaching a lead teacher (LT) designated in each school. The diagrams were revised part way through the project as the theory of change in each school evolved and were used as the basis of final evaluations to establish how the project implementation and contexts had shaped the actual outcomes. As such, they took into account factors including a high turnover of pupils (typical of the mobility of children in service families), changing school leadership and changing priorities driven by school inspection.

In order to draft and redraft the theory of change diagrams, the evaluation team spoke to the LPs on a regular basis. Throughout the project, both formal and informal group 
conversations occurred as and when opportunities arose, often in and around the network meetings where all LTs and LPs met. The LTs were interviewed as a group during the network meetings held in Terms 2, 3 and 4 of the SSIF project. The network meetings also provided an opportunity to gather observational data. Further interviews took place at the end of the project with the strategic lead, the project manager and the independent quality assurance consultant. Schools and LPs also provided project documentation for analysis. These data collection opportunities allowed the theory of change diagrams to be finalised and validated.

In Example 3, teacher coaching for enhanced speech, language and communication practices, focus groups were held before and after coaching. These were attended by nine teachers, who were middle and senior leaders from the two federated schools, including the executive headteacher. The sequence of three coaching sessions with seven teachers were audio-recorded for analysis. The recordings were transcribed and coded based on a revised version of coaching dimensions (Lofthouse et al., 2010) which included speech, language and communication needs specific content, interaction functions, co-construction and use of video and other resources. This combination meant that the participants' self-reported expectations and experiences of learning from coaching could be triangulated with evidence of the nature of their engagement with, and progression through, the coaching sessions.

Using the existing data, each example of coaching was reanalysed by the first author, enabling a reconsideration of each coaching provision as an activity system. Figure 1 was used as a base map for reviewing the provision and efficacy of the three coaching examples, allowing an articulation of their specific characteristics and efficacy. Activity systems are rarely stable, and the three evaluations had allowed changes over time to be recognised. The original research evidence was used to explore each coaching example as an activity system, with the object, subject, role of tools, and the influences of the rules, community and division 
of labour as key mediating artefacts used as categories for deductive reasoning. This allowed a reconsideration of the outcomes of each coaching example, as experienced individually and collectively by the participants. The study therefore provides a specific theorisation of 'the ways [the coaching elements] work together to explain how that particular system functions' (Strom and Viesca, 2020, p. 4), allowing the influences on the efficacy of the coaching provisions in each context to be better understood.

\section{Findings}

\section{Understanding the coaching examples as activity systems}

In each example, the object of the coaching provision was to address a specific challenge typical of educational contexts in England. Addressing the challenge was considered necessary to secure the quality of education within specific cultural and political framings of the purpose of education. Coaching was adopted as it acknowledges the role of the professionals' learning and wellbeing in enabling them to meet such challenges and positions the coachee's self-reflection and effective decision-making as central. In Example 1, the challenge was the need to both retain and develop school leaders in order to create a more sustainable profession able to lead the work of schools. In Examples 2 and 3, the challenges were the need to develop teachers' pedagogic knowledge and skills to ensure enhanced learning opportunities for children who fell into groups proven to underperform in relation to average. In Example 2, this group were children of military families with high mobility rates, and in Example 3, they were children with English as an additional language (EAL) in deprived urban communities. The coaches were the subjects, recruited to work in each educational context. The object of the coaching was to support the coachees to experience personal and/or professional growth underpinned by a motivation to enhance their capacity or repertoire to support the learning or development of others (colleagues and pupils/students) as defined by the educational challenge. 


\section{Example 1: Headteacher coaching}

Subject and tools. The headteachers in Example 1 particularly valued the fact that their coaches were not connected to their school and had no vested interests. The independent space created was considered beneficial and allowed the headteachers to get to the bottom of difficult issues. They talked about confidentiality and 'head space' being maintained which allowed them to 'have honest and open conversations that lead to clarity in direction'. They stated that this does not happen with anyone else - for example, with union reps, governors or other headteachers. The 10 coaches had all been practising coaches for between four and 20 years and all provided coaching beyond this specific programme and had a depth of knowledge and experience that they brought to bear in coaching practice. The coaches also participated in individual and group supervision. The programme director explained this saying,

Professional qualification is important but does not guarantee credibility. It is about sharing our values. My coaches have to have a good understanding of life in the education sector and what life is like for school leaders. They have to show depth in coaching as a reflective process. They have to be able to conduct long conversations and ask key questions. (Programme director)

The coaching model adopted was described as having an ontological root which the director of the coaching company described as being "designed to enable headteachers to lead with integrity out of who they are" (Lofthouse and Whiteside, 2020, p. 8). Question themes acted as a tool which could be addressed in the manner that was most appropriate for each individual coachee, as and when they arose within the coaching conversations.

Mediating artefacts. The most explicit of the rules in the coaching activity systems of the three examples was the contracting at the beginning of the headteacher coaching. This 
contracting helped to develop a shared understanding of what was to come, including when a coach might signpost to a headteacher how their needs may be addressed beyond the coaching (e.g. by counselling). Other framing rules shaped the expectations and coaching sessions; the headteacher remained at the centre of the conversation by setting the agenda, and their coach helped them to make meaning and find depth of purpose in their own leadership journey.

The locations and venues of the coaching conversations were also relevant. The coaching took place off-site (hence can be recognised as a rule) in places where the headteachers felt comfortable. These venues included coffee shops, hotel lounges, dedicated coaching spaces in the coaches' own settings, including garden studios, and even walking, both in countryside and urban areas. All the headteachers travelled some distance for their coaching sessions as this contributed to the confidentiality of the conversations. This travelling time, either by train or car, was seen by the headteachers as part of their thinking time both prior to and following on from the coaching conversation itself.

Access to coaching did not rely on gatekeeping or funding at school level. Despite this, the influence of the school as a community in shaping the coaching was clear because dilemmas in the school drove much of the conversations. Both the headteachers and the coaches described headship as made up of many challenges and acknowledged that headteachers had limited control over some of the dimensions of the role. One headteacher wrote that 'the demands of headship can be overwhelming'. During an interview, another headteacher described school as 'an oil tanker ... to turn things around takes a long time and it's having a sense of what is achievable and manageable'. The coaches' understanding of this was heightened by their experiences in multiple coaching roles. As such, they had sequences of coaching conversations with many headteachers, and they naturally synthesised the patterns of the challenges that the headteachers faced. 
Sense making and outcomes. The headteachers experienced coaching as supporting them to build their capacity for managing the complexities of school and as influencing the work of their colleagues. In the focus group, several key outcomes were shared with the discussion leading to a consensus that the following impacts were commonly felt: 'having time to prioritise the issues that need resolving', 'normalising the intricacies of relationships in the school' and 'developing decision-making, strategic ability, soft skills to influence others'. The ontological model of coaching used with the headteachers was designed to support them in identity work. Table 2 (Lofthouse and Whiteside, 2020, p. 19) illustrates this occurring as a sense-making process. It lists some of the coaches' responses about how they defined successful coaching, which are compared with comments from the headteachers. This helps to demonstrate that the headteachers became more reflective as they gained space and support through the coaching conversations. It is the reflection which acts as a sense-making process.

\begin{tabular}{|l|l|}
\hline \multicolumn{2}{|c|}{ Headteachers engaging with identity work: becoming more reflective } \\
\hline $\begin{array}{l}\text { Coaches' definitions of successful coaching process (all } \\
\text { quotes) }\end{array}$ & $\begin{array}{l}\text { Headteachers' reflections on the process of coaching } \\
\text { (all quotes) }\end{array}$ \\
\hline $\begin{array}{l}\text { I would be looking for some sort of shift in them, greater } \\
\text { self-awareness, ability to step away, better able to self- } \\
\text { coach to ask themselves questions that really matter, } \\
\text { getting away from the busy treadmill. }\end{array}$ & $\begin{array}{l}\text { Being guided in self-reflection and made to 'dig deeper'. } \\
\text { (Focus group) } \\
\text { The coach doesn't supply answers but helps to uncover } \\
\text { answers that have been there all the time. (Interview) } \\
\text { Ability to unpack complex issues, gain perspective and } \\
\text { find ways forward. (Focus group) }\end{array}$ \\
\hline $\begin{array}{l}\text { I want them to have conversation about their strengths. } \\
\text { Time to reflect on positives rather than only hearing the } \\
\text { negatives. (Focus group) } \\
\text { Coaching allows and helps you to realise you are being } \\
\text { rational about situations. (Focus group) }\end{array}$ \\
$\begin{array}{l}\text { The space to stop and actually consider what I do well as a } \\
\text { It can be emotional. It is helpful to share this with someone } \\
\text { who knows and understands the job and listens with an } \\
\text { informed ear. }\end{array}$ & $\begin{array}{l}\text { Coaching was nurturing ... indulging myself in proper } \\
\text { strategic work. (Interview) } \\
\text { Coaching was supportive emotionally. (Interview) }\end{array}$ \\
\hline $\begin{array}{l}\text { Coaching usually raises questions about professional } \\
\text { identity. It goes beneath the school's performance. It } \\
\text { includes consideration of who they are and is integrated } \\
\text { with professional identity. }\end{array}$ & $\begin{array}{l}\text { It gives me the space to look at things from a different } \\
\text { perspective and to think about how I will change my } \\
\text { management style. (Questionnaire) } \\
\text { Coaching makes me feel like I own the solutions and that I } \\
\text { can move forward with them with confidence. (Interview) }\end{array}$ \\
\hline
\end{tabular}

Table 2. Identity work through coaching; linking stated success criteria and outcomes of headteacher coaching (Example 1) 


\section{Example 2: Teacher coaching for metacognitive pedagogies}

Subject and tools. Unlike Example 1, the coaches in Example 2 had no experience as coaches prior to being appointed as LPs to the SSIF project. When they were first appointed, the LPs were not experts in metacognition nor how it might be delivered in the classroom in the context of mathematics. During their first half term in role, they sought training, attended meetings and read widely. They then pooled their training and shared what they had learnt. According to the project manager, the LPs 'rapidly' become experts in the area; indeed, during the project, two of the LPs became specialist leaders of education (SLEs), with the third already having that status prior to appointment. Following their self-determined induction period, the LPs combined their newly gained insights with their previous experiences as teachers and middle leaders to conclude that a critical component of their LP role would need to be provision of coaching within the project. Having made sense of the contexts of the 10 project schools and how to divide their time supporting the LTs in each, they chose a very practical coaching approach, which was based on modelling mathematics lessons using metacognitive pedagogies, joint planning with the LT, co-teaching and debriefing. The term 'specialised contextualised coaching' was coined to describe this.

Responses from LTs during the focus group at the end of the SSIF project demonstrated that they found the ongoing coaching provision beneficial. They appreciated how the project was tailored to meet the needs of the individual schools, with one LT commenting, 'often it's a one model fits all and that does not work'. They were particularly positive about working with the LP over a period of time, as one LT explained in the focus group: 'With this you get continued support. Other training sessions are an hour here and an hour there and there is no one afterwards to help you or check on you or to discuss it with'.

Mediating artefacts. A distinctive feature of the SSIF project was the allocation of release time to the LTs to work with the coaches; this is part of the division of labour of the 
activity system. As the programme evolved, the LTs also formed a network who met and worked with each other. Despite the LTs all being employed in schools associated with the TSA, their participation in a subject network was a novel experience. Towards the end of the project, the LTs also visited each other's schools to see each other teach and to discuss the metacognitive pedagogic approaches that were being developed through the project. In the focus group, this activity was reflected on as a highlight. They said that they found it beneficial 'seeing other practitioners', and by being observed, they experienced the 'benefit of reassurance'. This new community, built on new divisions of labour, helped to maintain and focus the object of the activity system.

Sense making and outcomes. The LTs felt it had made them more reflective practitioners. When reflecting on the experience, one LT described it as the best continuing professional development they had ever had. They became more aware that transformation of practice took time. A significant and measurable impact of the SSIF project was on the LTs' increasing self-efficacy, as part of the process was a heightened chance to make sense of self as their new responsibilities emerged. They thus began to consider potential future professional roles resulting from the coaching and wider project engagement. Of nine LTs engaged throughout the programme, five had become SLEs by the end of it. Several of the LTs were more actively involved in action planning and feeding into school development plans. As one LP commented, 'For [the LTs], they will go into leadership roles and think, change does not happen overnight. They are going to have that mind-set and that's a fantastic place to be in moving forward and moving schools forward'. The SSIF project, which was led by three female LPs and sustained by nine female LTs, allowed women to model and gain leadership and develop professional confidence (no male LPs were appointed, and the one male LT only partially engaged in the project). The Department for Education acknowledges the need to further develop women in educational leadership given that they are 
underrepresented at leadership level in both primary and secondary schools. This project achieved broad strategic school improvement outcomes, even though these were not articulated as a gendered issue in the theory of change underpinning the project, by showing good evidence of the capacity to grow whole-school improvement, especially in developing middle leaders.

\section{Example 3: Teacher coaching for enhanced speech, language and communication practices}

Subject and tools. In contrast to Example 2, the two coaches in Example 3 had never been teachers, but each had 20 years of experience as speech and language therapists and specialised in working with children. They had high levels of contextual knowledge related to the demographics and needs of the children in the city. They had spent two years developing a video-based coaching approach which allowed them to work directly with teachers to support pupils with a range of speech, language and communication needs (SLCN) and pupils with EAL (Lofthouse et al., 2016; Lofthouse et al., 2018).

The coaching provision relied on the speech and language therapists' specialist professional knowledge and the skills and techniques they had developed during previous coaching work. Unlike some coaching models, the approach included giving advice and guiding teachers to be more curious and insightful with respect to their pupils' SLCN. The explanatory language they used reflected this, bringing together the two professional domains. Video supported shared scrutiny of teaching and learning between the coach and the teacher, and it enhanced the teachers' capacity to focus on the SLCN of individual children, as reported by one teacher: 'I thought they're all "the same ability" but they're completely different. I've got 8 to ten months, 22 to 26 , year ones, and they're all completely different [referring to early years ages and stages]'. Such insights led to more attuned pedagogic decision-making as described by two teachers in the focus group: 'Things like group work, 
body language, using images with the words, using vocabulary that they could understand, giving short and simple instructions, repetition' and 'the positioning of children during an adult directed session'.

Mediating artefacts. A concern raised by teachers and senior leaders prior to coaching was the potential additional workload, especially as managing workload was a high priority for which school leaders were held to account through inspection. Workload can be recognised as a component of division of labour within an activity system. In the postcoaching focus group, the consensus was that workload had not increased:

I think the key part I took from it is that you just need to be reflective in all you are doing. ... It was everyday tweaks that made life a little easier ... it reduced my workload a little bit. Something as small as repositioning children within a group, to get them communicating with each other and join in, it did happen. So, the advice she gave, although very small, did have impact. (Teacher in focus group)

The discussion around workload gave additional insight into the perceived value of the coaching, as one teacher explained: 'Workload is one of those things that if you see the value of what you are doing it doesn't feel the same as if you don't'.

Sense making and outcomes. Analysis of the coaching sequences demonstrated a common pattern, which had not been specifically articulated in the design of the coaching provision but indicated how sense making emerged in relation to the object of the activity system. There were two elements to this. First, the video-based coaching sessions typically had three distinguishable phases:

1. Orientation phase: agreeing the SLCN focus

2. Shared scrutiny phase: coach and teacher reviewing classroom practice with respect to the SLCN focus, using video, recall and relevant documents as stimulus and drawing 
on existing professional knowledge (from the two professions), triggering some dissonance and realisation for the teacher

3. Moving forward through co-construction phase: coach prompting further reflection, problem-solving, and suggestions for developing practice being co-constructed

Second, there was evidence of some progression in sense making through the sequence. This is illustrated in Table 3, which summarises the features of one teacher's coaching sequence.

Changes occurred over time in the dynamic roles that the coach and teacher took in the conversations, the specificity of the SLCN focus under discussion and the teacher's familiarity with relevant vocabulary, concepts and tools to help her make more informed judgements which helped the teacher move from being relatively tentative to more committed in pedagogic decision-making.

\begin{tabular}{|c|c|c|c|}
\hline Phase & Coaching session 1 & Coaching session 2 & Coaching session 3 \\
\hline Orientation phase & $\begin{array}{l}\text { Coach asks opening question and teacher } \\
\text { states general SLCN as focus and then } \\
\text { refines this to phonics, leading to some } \\
\text { initial sequences of coach questions and } \\
\text { teacher evaluations. }\end{array}$ & $\begin{array}{l}\text { Coach asks opening question and teacher } \\
\text { states age/phase SLCN development as } \\
\text { focus, and goes on to begin to describe } \\
\text { relevant aspects of lesson and pupils' } \\
\text { responses. }\end{array}$ & $\begin{array}{l}\text { Coach asks opening question and } \\
\text { response is immediate, detailed and } \\
\text { specific from teacher with focus } \\
\text { returning to age/phase SLCN } \\
\text { development and appropriate teaching } \\
\text { decisions for specific group of children. }\end{array}$ \\
\hline $\begin{array}{l}\text { Shared scrutiny } \\
\text { phase }\end{array}$ & $\begin{array}{l}\text { Detail of practice unpacked through } \\
\text { questions and answers, with specific } \\
\text { reference made to the teaching phonics. } \\
\text { Use of video prompts teacher evaluation } \\
\text { and realisation (dissonance). Focus on } \\
\text { how teacher and pupils are interacting } \\
\text { and on how pupils are interacting with } \\
\text { each other in relation to using phonics. }\end{array}$ & $\begin{array}{l}\text { Close attention paid to understanding } \\
\text { age/phase SLCN of specific children, } \\
\text { triggered by video evidence and joint } \\
\text { reference to age/phase chart. Significant } \\
\text { teacher evaluation, with the coach } \\
\text { questioning and checking judgements. } 2 \\
\text { clear sequences of the coach asking } \\
\text { challenging questions, followed by } \\
\text { teacher review/evaluation, coach } \\
\text { prompting further reflection and teacher } \\
\text { realisation about actual (rather than } \\
\text { assumed) age/phase of children. }\end{array}$ & $\begin{array}{l}\text { Discussion very much led by teacher } \\
\text { who uses recall, video and age/phase } \\
\text { chart to undertake an informed analysis } \\
\text { of the children in the 'low ability group'. } \\
\text { Supported by the coach she challenges } \\
\text { her own assumptions and recognises the } \\
\text { wide disparity in age/phase between the } \\
\text { children. The coach reassures her that } \\
\text { she is making accurate judgements and } \\
\text { they discuss the significance of this for } \\
\text { each child and for the teacher's practice. }\end{array}$ \\
\hline $\begin{array}{l}\text { Moving forward } \\
\text { through co- } \\
\text { construction phase }\end{array}$ & $\begin{array}{l}\text { Ideas for altering practice emerge, both } \\
\text { coach and teacher make suggestions } \\
\text { specific to phonics teaching for these } \\
\text { pupils. Teacher makes some } \\
\text { commitments to try things out, including } \\
\text { more planned and consistent use of } \\
\text { visual aids. Reference made to ideas } \\
\text { from specific training sessions } \\
\text { previously attended. }\end{array}$ & $\begin{array}{l}\text { Sequence of suggestions from both } \\
\text { coach and teacher, building on one } \\
\text { another's contributions, leading to } \\
\text { consideration of future teaching practices } \\
\text { to suit enhanced understanding of } \\
\text { children SLCN development. }\end{array}$ & $\begin{array}{l}\text { The teacher comes up with very specific } \\
\text { suggestions about better meeting the } \\
\text { children's age/phase development in her } \\
\text { teaching, supported by layering in of } \\
\text { further ideas by the coach. Most of the } \\
\text { talking is by the teacher who considers } \\
\text { and commits to appropriate } \\
\text { differentiation and universal teaching } \\
\text { approaches. }\end{array}$ \\
\hline $\begin{array}{l}\text { \% contribution } \\
\text { (word count) }\end{array}$ & $\begin{array}{l}\text { Coach: } 37 \% \\
\text { Teacher: } 63 \%\end{array}$ & $\begin{array}{l}\text { Coach: } 58 \% \\
\text { Teacher: } 42 \%\end{array}$ & $\begin{array}{l}\text { Coach: } 36 \% \\
\text { Teacher: } 64 \%\end{array}$ \\
\hline
\end{tabular}

Table 3. An example of one teacher's progression through a sequence of specialist coaching focused on speech, language and communication needs and pedagogy (Example 3) 
Like in Example 2, there was evidence that the experience of being coached had heightened the willingness and confidence of teachers to work collaboratively with others in the future: 'If you find provision that makes a difference you need to keep doing that. We need to think about building our own internal capacity for coaching' (Senior leader in focus group). It gave teachers insights and confidence in new skills for wider professional roles, such as mentoring: 'I mentor student teachers, and I didn't realise how to break down everything with my student; [coaching] helped me reflect on my practice,' (Teacher in focus group). This was further developed by the executive headteacher who considered that teachers gaining confidence in the efficacy of their practice was valuable in supporting ongoing school improvement.

\section{Discussion}

This study illustrates how activity systems can be used as an analytical tool to understand the functions and efficacy of coaching provision in education by reconsidering examples of coaching through their object, subject, tools and other mediating artefacts. As an analytical tool, the activity system thus enables a fuller understanding of the extent to which a specific coaching provision meets its core objectives in its own context and creates additional impact. The analysis also affords insights into the mechanisms and influences that are active in the system.

Appreciating the diversity of coaching identified by Grant (2013) rather than trying to narrowly frame it as a monolithic activity is valid if we position coaching as having potential to support change in complex and diverse education settings. The evidence offered through the three examples illustrates how coaching influenced the working lives of professionals facing a range of challenges in 51 schools in England. By framing unique examples of coaching in education as activity systems, it is possible to demonstrate that coaching has a range of functions (both intended and consequential). In education policy, there is an 
imperative to find 'what works?' from research as a precursor to scaling up an intervention or approach. Each coaching programme requires an investment of time and money, but determining a cost-benefit analysis of each would require sophisticated analytical tools and a degree of supposition. This does not imply that the value of coaching is intangible or limited. The coaching exemplified here can be recognised as effective but may not necessarily be readily scaleable. To follow Biesta's (2020) argument, we must know what different coaching provisions or approaches are effective for and for whom (their function). The coaching activity systems detailed through this study help us to answer those questions. In all three examples, coaching provision created opportunities to explore and reimagine professional identities and meaning (Bush et al., 2013). While this is hard to measure in output or cost terms, it does remind us that nothing can be scaled up in education without paying attention to how individuals develop as agents for change. Rather than playing to the demands to roll out and scale up at the system level, coaching allows practitioners to focus on the essential relational human scale.

The coaches in these examples were not true peers of the teachers or headteachers. While their levels of independence varied (influenced by who funded them to do the work), the coaches were not employed as staff by the schools in which the coachees worked and, in some examples, had not held equivalent professional roles. Coaches were not trying to manage multiple roles in relation to the workplace or coachee, which Killion (2009) recognised were hard to balance. In this respect, the coaching was 'cleaner' and easier to contract (Lee, 2013). It is therefore not possible to use these examples to refute the claim made in earlier research (Lofthouse and Leat, 2013), itself based on analysis using activity theory, of the problem of dominant performativity cultures reducing the potential of peer coaching. Instead, this new analysis of coaching provision as individual activity systems helps to make sense of the extent to which non-peer coaching can correspond with the wider 
objects of education, thus providing exemplary detail for the definitions of coaching in education, including the one framing this research and the definition indicated by van Nieuwerburgh (2012) and Campbell and van Nieuwerburgh (2017).

What the coaches in these new examples brought into each education context was relevant specialist expertise which was part of both the historical and present dimensions of the activity systems (Engeström, 1987, 1999, 2001, 2007). In each example, specific coaching approaches were adopted, which had either been developed over time by the coaches or programme directors for work in similar education contexts or had evolved during the projects. The tools used by the coaches (e.g. frameworks of questions, co-teaching, video) helped to facilitate coaching as a developmental process. The role of other mediating artefacts such as rules, community and the division of labour was also evident in the three examples. Each coaching example was framed by the shared motivations of the addressing specific educational challenges.

A further consideration in coaching efficacy is for whom it has an effect. The nature of self-reporting in these small qualitative examples draws attention to the impact of coaching on the coachees during or soon after their engagement with coaching. In each example, the methodologies did allow the experience of coaching to be traced from beginning to end, but not beyond the project timespan. As is often the situation, the funding constraints or project timeframes meant that the duration of the coaching provision itself was also time limited. While it is not possible here to report the full range of outcomes of each example of coaching, we present evidence of how the practitioners being coached engaged in sense making as a process which influenced the outcomes that they experienced individually and collectively. The three coaching provisions were reported by coachees as having positive impacts, and the outcomes could not be wholly predicted by the stated object of each activity system. Perhaps one of the most valuable insights comes from the evidence of how coaching, despite being an 
individualised one-to-one process, produces ripple effects with the potential to impact more widely not only on the coachee's educational setting but also on their future professional roles and working relationships with others. This is grounds for optimism and supports the proposition of coaching as a transformational relationship (Fletcher, 2012).

\section{Conclusion}

By framing this new analysis of three coaching examples through activity systems, it has been possible to interrogate the outcomes of coaching used in education and how they come about. There is evidence of the coaching leading to professional and personal formation, allowing the coachee to experience growth, development and self-efficacy through the opportunities for reflection and learning through interpersonal and sustained dialoguebased practice. The proposition is thus that to better understand the functions and efficacy of coaching in education, due attention needs to be paid to the purposes and elements of each approach. Coaching in education is a diverse and divergent practice rather than a monolithic one. Understanding the characteristics of different provision as individual and situated activity systems generates opportunities for insights into how and for whom coaching has an impact.

\section{References}

Bachkirova, T., Cox, E. \& Clutterbuck, D. (2014), “Introduction”, Cox, E., Bachkirova, T. and Clutterbuck, D. (Ed's), The Complete Handbook of Coaching (2nd ed). SAGE, London. pp.1-18

Ball, S.J. (2003), “The teacher's soul and the terrors of performativity”, Journal of education policy, Vol. 18 No. 2, pp.215-228.

Biesta, P.G. (2020), Educational research: an unorthodox introduction. Bloomsbury, London, UK.

Briggs, A.R.J. (2007), "The use of modelling for theory building in qualitative analysis", British Educational Research Journal, Vol. 33 No. 4, pp. 589-603.

Buck, A. (2020), The Basic Coaching Method, Cardogan Press, London, UK 
Bush, M.W., Ozkan. E. and Passmore, J. (2013), “The development of meaning and identity within coaching", Passmore, J., Peterson, D.B. and Friere, T. (Ed's), The WileyBlackwell Handbook of the psychology of coaching and mentoring, Wiley-Blackwell, UK, pp.58-67

Campbell, J. and van Nieuwerburgh, C. (2017), The leader's guide to coaching in schools. Thousand Oaks, CA: Corwin Press.

Cordingley, P., Higgins, S., Greany, T. et al. (2015). Developing great teaching: Lessons from the international reviews into effective professional development. Teacher Development Trust. Available at: tdtrust.org/about/dgt (accessed 2 April 2020). Engeström, Y. (1987), Learning by expanding: an activity-theoretical approach to developmental research, Orienta-Konsultit, Helsinki.

Engeström, Y. (1999), "Activity theory and individual and social transformation", Engeström, Y. Miettinen, R. and Punama'ki, R-L., (Ed's) Perspectives on Activity Theory, Cambridge University Press, Cambridge.

Engeström, Y. (2001), "Expansive learning at work", Journal of Education and Work, Vol. 14 No.1, pp.133-156.

Engeström, Y. (2007), "Putting activity theory to work: the change laboratory as an application of double stimulation" Daniels, B., Cole, M., and Wertsch J.V., (Ed's) The Cambridge companion to Vygotsky, Cambridge University Press Cambridge.

Fletcher, S. J. (2012), Coaching: an overview, in Fletcher, S.J. and Mullen, C.A. (Eds), The SAGE Handbook of mentoring and coaching in education, SAGE, London, UK.

Grant, A., (2013), “The efficacy of coaching”, Passmore, J., Peterson, D.B. and Friere, T. (Ed's), The Wiley-Blackwell Handbook of the psychology of coaching and mentoring, Wiley-Blackwell, UK, pp.15-39.

Grant, A. and O'Connor, S. (2019), “A brief primer for those new to coaching research and evidence-based practice", The Coaching Psychologist, Vol. 15, No.1. pp. 3-10.

Gu, Q., Rea, S., Smethem, L., Dunford, J., Varley, M., Sammons, P., Parish, N., Armstrong, P., and Powell. L. (2015), Teaching Schools Evaluation, Final Report for National College for Teaching and Leadership, England, UK. Available at: https://www.gov.uk/government/publications/teaching-schools-evaluation-finalresearch-report

Hollweck, T. (2017). "Threading the Needle: Examining the Mentoring and Coaching Fellowship of the Western Quebec School Board”, Kutsyuruba, B. and Walker, K.D., 
(Ed's.), The bliss and blisters of early career teaching: A pan-Canadian perspective, Word \& Deed Publishing, Burlington, ON. pp.205-226

Killion, J. (2009), Coaches roles, responsibilities and reach, in Knight, J. 2009, (Ed)

Coaching approaches and perspectives, Corwin Press, Thousand Oaks, CA.

Knight, J. (2017), The impact cycle: What instructional coaches should do to foster powerful improvements in teaching. Corwin Press, Thousand Oaks, CA.

Kraft, M.A., Blazar, D. and Hogan, D. (2018), "The effect of teacher coaching on instruction and achievement: A meta-analysis of the causal evidence", Review of Educational Research, Vol. 88 No. 4, pp.547-588.

Kuusisaari, H. (2013), “Teachers' collaborative learning - development of teaching in group discussions", Teachers and Teaching: Theory and Practice, Vol 19. No 1 (2013), pp. $50-62$

Laing, K. and Todd, L. (Ed's). (2015) Theory-based methodology: using theories of change in educational development, research and evaluation. Research Centre for Learning and Teaching, Newcastle University.

Lee, R. J. (2013), “The role of contracting in coaching: balancing individual client and organizational issues" Passmore, J., Peterson, D.B. and Friere, T. (Ed's), The WileyBlackwell Handbook of the psychology of coaching and mentoring, Wiley-Blackwell, UK, pp.40-57.

Leont'ev, A. N. (1981), “The problem of activity in psychology”, Wertsch, J. (Ed.), The concept of activity in Soviet psychology. Armonk, N.Y.Sharpe.

Lofthouse, R. (2019), "Coaching in education: A professional development process in formation", Professional Development in Education, Vol. 45 No. 1, pp. 33-45.

Lofthouse, R., Flanagan, J. and Wigley, B. (2016): A new model of collaborative action research; theorising from inter-professional practice development, Educational Action Research, Vol. 24 No. 4, pp 519-534 DOI: 10.1080/09650792.2015.1110038

Lofthouse, R. M., Flanagan, J., \& Wigley, B. (2018). Talking it through: using specialist coaching to enhance teachers' knowledge from speech and language sciences. Impact: Journal of The Chartered College of Teaching, (2), 85-88.

Lofthouse, R., and Leat, D. (2013), "An activity theory perspective on peer coaching", International Journal of Mentoring and Coaching in Education, Vol. 2 No. 1, pp. 8-20. https://doi.org/10.1108/20466851311323050

Lofthouse, R., Leat, D., Towler, C., Hall, E. and Cummings, C. (2010), Improving Coaching: Evolution Not Revolution, CfBT Education Trust, Reading. Available at 
https://www.educationdevelopmenttrust.com/our-research-andinsights/research/improving-coaching-evolution-not-revolution

Lofthouse, R., and Rose, A. (2019), Evaluation of the Metacognition in Service Schools SSIF Initiative: An end of project report for the Swaledale Teaching Alliance, Project Report. Available at https://www.leedsbeckett.ac.uk/-/media/files/schools/school-ofeducation/swaledale-ssif-project-evaluation-metacognition-in-maths.pdf?la=en

Lofthouse, R and Whiteside, R (2020) Sustaining A Vital Profession: Evaluation Of A Headteacher Coaching Programme. Project Report. Leeds Beckett University. Available at https://www.leedsbeckett.ac.uk/-/media/files/schools/school-ofeducation/sustaining-a-vital-profession--finalreport.pdf?la=en\&hash=246B2F6A411111B23E9522E7220BB6BE

Sherrington, T. and Caviglioli, O. (2020), Teaching WalkThrus: Five-step guides to Instructional Coaching, John Catt Educational Limited, London, UK.

Strom, K.J. and Viesca, K.M. (2020), “Towards a complex framework of teacher learningpractice", Professional Development in Education, DOI: $10.1080 / 19415257.2020 .1827449$

Thorpe, V. and Kinsella, V. (2020), “Secondary school arts teachers” practice autonomy perceptions in New Zealand and England", Journal of Curriculum Studies, DOI: $10.1080 / 00220272.2020 .1767215$

van Nieuwerburgh, C. (Ed) (2012), Coaching in education: getting better results for students, educators and parents. Karmac, London, UK.

van Nieuwerburgh, C. (2017), An introduction to coaching skills: A practical guide (2 ${ }^{\text {nd }}$ ed.). SAGE, London, UK.

Vygotsky, L.S., (1978), Mind in society: the development of higher psychological processes. Cambridge, MA: Harvard University Press.

Vygotsky, L.S., (1986), Thought and Language. Cambridge, MA: MIT Press.

Wilson, V. (2014), "Examining teacher education through cultural-historical activity theory", TEAN Journal Vol. 6 No. 1, pp. 20-29. 